\title{
Critical Argument and Writer Identity: Social Constructivism as a Theoretical Framework for EFL Academic Writing
}

Critical Inquiry in Language Studies, 12(3), 184-207 (September 2015)

Jim McKinley, University of Bath

\section{Abstract}

This article makes the argument that we need to situate student's academic writing as socially constructed pieces of writing that embody a writer's cultural identity and critical argument. In support, I present and describe a comprehensive model of an original EFL writing analytical framework. This article explains the interrelationship between the elements of cultural practices in academic discourse, writer identity, and critical thinking, and argues how this is influenced by the sociocultural values of academic discourse. This interrelationship is realized by viewing EFL writing through a social constructivist lens, showing how critical thinking processes are shaped by awareness of the sociocultural conventions of academic discourse, and how critical thinking arises from a writer identity aligned with the culture of English academic writing.

\section{Introduction}

This article explores the literature surrounding L2 academic writing and socio-constructivist theory in order to propose an original theoretical framework for understanding written academic texts of English as a Foreign Language (EFL) students. This model will be useful for instructors, researchers, and students of EFL writing as it is designed to reveal the benefits to these groups of focusing particularly on critical argument and writer identity. The central philosophy behind the decision to focus on the areas of critical argument and writer identity in understanding EFL students' academic writing abilities is social constructivism-a learning theory based on the ideas of Vygotsky (1978) that human development is socially situated and knowledge is constructed through interaction with others. Creswell (2009) asserts that social constructivism serves as a useful theoretical framework as it allows for necessary qualitative analysis to reveal insights on how people interact with the world. 
Social constructivist theory asserts that people's ideas coincide with their experiences and that writers build on their socio-cultural awareness, a key point in identity construction.

In this article, I first present a brief review of the main theories that underpin the theoretical framework, which are sociocultural theory, identity construction theory, and critical argument theory. I then discuss the literature that provides brief background information on social constructivism in academic writing research, followed by a focus on cultural practices in academic discourse in the form of an overview of relevant studies utilizing social constructivism as a base theory. Then, I analyze some current studies in EFL and L2 writing in order to justify why social constructivism is an appropriate lens through which to view EFL writing. This is followed by an analysis of the elements of cultural practices in writer identity research, and a discussion of critical thinking research. This discussion then leads to the presentation of the proposed theoretical framework, underpinned by a summary of the key concepts that serve as the components of the framework. Finally, I bring together the analysis of all three elements—cultural practices in academic discourse, writer identity, and critical thinking-in order to support the argument that the interrelationship between them is influenced by the sociocultural values of academic discourse. To conclude, I briefly highlight some implications this theoretical framework presents.

I maintain that developing critical argument is a social activity, meant to generate a discussion designed to resolve some difference of opinion (van Eemeren \& Grootendorst, 1984). This perspective sees critical argument as a design theory that combines rationality with social and political contexts. It provides a way of evaluating opposing positions in a way for the writer to gain insight from them, generate a shared construction of knowledge, and 
avoid rhetorical fallacies (van Eemeren \& Grootendorst, 1992). With this theoretical insight, this article serves to explain how EFL student writers make arguments to generate a discussion that reflects the social and political context of the immediate writing task.

\section{A brief summary of each of the main theories}

Before the literature surrounding a social-constructivist view of L2 academic writing is discussed in depth, I will first define the three main theories that underpin this article: sociocultural theory; identity construction theory; and critical argument theory.

Sociocultural theory, as Lantolf and Thorne (2006) point out, clearly connects sociointeractional constructivist theory with a collaborative learning environment such as university EFL writing classrooms. Through the incorporation of sociocultural conventions of academic discourse, it allows for the students' and teachers' social and cultural backgrounds and positionalities to inform a written analysis in valuable ways, and to recognize the significance this has on university students engaging critical thinking skills in establishing writer identity and developing critical argument in learning academic EFL writing.

Identity construction theory involves the formation of both cultural identity and academic identity. In cultural identity construction, social interaction is the basis for people's understanding of their position in relation to others within the same cultural community. Identity construction theory helps in explaining the ideational and interpersonal relationships involved in forming an academic identity. Ivanič (1998) built on this theory to explain that the construction of academic writer identities is dependent on social and 
cultural factors and is developed in written discourse when a writer makes particular language choices in attempts to persuade readers.

Critical argument theory maintains that an argument generates a discussion in the shared construction of knowledge (van Eemeren \& Grootendorst, 1992). As it pertains to EFL writing, the theory builds on the idea that writers use different ways and forms of developing an argument. Different ways might be taking a stance first based on one's own schemata and later supporting it with source evidence, or reading widely first and deciding on a stance based on the evidence. Different forms might include deductive or inductive writing, or using an autobiographical, authorial and/or discoursal self (Clark \& Ivanič, 1997). In the development of critical argument in written discourse, EFL student writers must exercise critical thinking skills. This is done in the reception of writing instruction in the classroom, and in the expression and development of the thesis in their written texts.

\section{Why and how the components work as a lens through which to view writing}

Each of these components has been identified for their value as perspectives from which to view writing, in particular EFL academic writing. In this section, I explore social constructivism in academic writing research in order to argue that each component is an appropriate lens. First, the sociocultural component is involved in the form of sociocultural conventions that shape critical thinking processes, requiring certain critical thinking operations in the enactment of these conventions during the writing process. Second, the identity component is recognized in the process of constructing a cultural identity within the academic community in which the writing is produced through interaction with texts that require students to incorporate the intercultural challenges they face into their schemata. 
Finally, the argument component is examined for its role in engaging student writers' critical thinking processes through the practice of developing an argument within an academic community and interacting with texts in distinguishing between appropriate and inappropriate evidence for claim support.

\section{The sociocultural component}

In a constructivist approach, the focus is on the sociocultural conventions of academic discourse such as citing evidence, hedging and boosting claims, interpreting the literature to back one's own claims, and addressing counter claims. These conventions are inherent to a constructivist approach as they place value on the communicative, interpersonal nature of academic writing with a strong focus on how the reader receives the message. The act of citing others' work is more than accurate attribution; it is an important exercise in critical thinking in the construction of an authorial self (Scollon, 1994). The act of interpreting the literature sees the writer function as a guide. Hyland (2004) explains that the writer acts "as a primary-knower in assisting novice readers toward a range of values, ideologies, and practices that will enable them to interpret and employ academic knowledge in approved academic ways" (p.121). The act requires writers and readers to enact critical thinking in imagining each other's purposes and strategies, and taking on those imaginations when writing or interpreting a text.

Hedging and boosting claims, and addressing counter claims, all fall under the umbrella of interpersonal metadiscourse, which allows writers to establish a standpoint from which to position their claims and their readers. According to Hyland (2004), hedging and boosting 
claims is a writer intervention and interpersonal strategy that expresses doubt and caution in the knowledge making process. Hyland emphasizes, "it is at the heart of the interactions of academic writing-and is a major component of the rhetorical expression of the readership between writer and reader" (2004, p.87). In addressing counter claims, when mitigating their introduction (Barton, 1995) through the use of contrastive connectives like however, writers are constructing a cultural identity by taking an interpersonal approach.

\section{The identity component}

Constructivist learning has significant implications for the construction of cultural identity in that, for adult learners with many years of experience and accumulated schemata, new information must be connected to neurological structures already in existence. Cultural identity building is an ongoing process that is affected by various social, cultural and historical factors that are especially realized in education settings, as illustrated by GomezEstern, Amián, Sánchez Medina and Marco Macarro (2010, p.231):

[C]ultural identity is not an immutable "essence" placed in the heart of our mind, but a malleable process that is constructed in relation to the social settings (such as formal education) in which people participate.

The fact that the process in the construction of cultural identity is participatory allows learners to take individual ownership of that construction. It is important to note here that while the idea that voice, critical thinking, and textual ownership are considered mainstream ideologies of individualism in the United States (Ramanthan \& Atkinson, 1999), this is not a universally accepted idea in cross-cultural or EFL writing (Casanave, 2002)—discussed later in this article. 
In their examination of social constructivist theory, Stetsenko and Arievitch (1997) argue, "constructing the self and deconstructing it can be viewed as the two alternative strategies ensuing from the socioconstructivist approach" (p.159). They offer an analysis of the two divergent theoretical/methodological perspectives within the social constructivist framework: the first being discourse-based, which sees the self in the social reality of discourse; and the second a post-Vygotskian perspective, which sees a guided formation of the self. These two perspectives do not suggest that an individual is self-contained, but rather offer "a relational, contextualized account of the evolving self" (p.159).

Stetsenko and Arievitch (1997) go on to explain that the discourse-based approach is insufficient for identity construction in that it separates the self from its psychological processes. They assert that, like the post-Vygotskian approach, the central focus in discourse-based approaches is the idea that "language use is taken as a root metaphor for all human action, and conversation, dialogue, as the root model for the analysis of all mental processes" (p.162). Where the discourse-based approach diverges is in its methodological application, in which the positivist methods of a naturalist inquiry are altered in a deconstruction of the self, designed to reveal the social-cultural nature of phenomena. In contrast, the post-Vygotskian perspective focuses on the positivist methods of active coconstruction of the self.

\section{The argument component}

And finally, the practice of writing arguments is both a design theory and an inherently socially constructed activity. Writers engage in critical thinking in developing an argument in order to resolve conflicts through rational evaluation of opposing positions, distinguishing 
between appropriate and inappropriate evidence for claim support, and learning from the whole process. With regard to defining critical thinking in these terms, Giroux (1994) identifies a powerful definition borne from the positivist tradition in the applied sciences. He points out that while the practice of teaching analysis and evaluation in reading and writing tasks is getting students to exercise critical thinking, it is not rather so direct. Instead, Giroux suggests that while the kind of formal, logically patterned writing tasks students are often assigned offer learning opportunities, it is in the processes that occur outside the patterns that the students actually participate in critical thinking.

Giroux's point here is important in that it highlights the value of the thought processes involved in the developing of a critical argument. Critical thinking occurs in learning situations in which students are required to interact with their peers, generating a coconstruction of knowledge (van Eemeren \& Grootendorst, 1992), as well as with other texts. It occurs where writers have a sufficiently deep familiarity with the subject matter in order to evaluate and resolve conflicting positions, something only achieved through extensive critical reading (identifying appropriate evidence for claim support) and establishing a reliable voice in the academic community in which the writing is developed.

In the development of a critical argument, there are different "ways of arguing" that students may attempt, as defined by different disciplines and different writing tasks within those disciplines. Some disciplines or tasks may place more importance on synthesizing multiple sources than others that look more toward planning solutions. Hyland (2008) points out that this has pedagogical implications in that student writers need to be informed of the "purposes, genres and readers that ... students will need to communicate with" (p.105). 


\section{Cultural practices in EFL academic discourse}

I turn now to a focus on publications that explore cultural practices in academic discourse in order to argue that social constructivism is an appropriate lens through which to view EFL writing. As there is limited research on social constructivism in the EFL-specific context, the discussion in this section first explores publications on social constructivist research in L2 writing and includes a brief discussion of the distinction between research in L2 writing and EFL writing contexts.

A specific focus on social constructivist research in L2 writing was addressed in Santos' (1992) article in the inaugural issue of the Journal of Second Language Writing. Santos described L1 writing education as ideological and L2 writing education as pragmatic. This description was offered in an analysis of the differences in social constructivist approaches in L1 and L2 writing. Santos claimed L1 composition to be ideological because of its focus on power and politics. Social constructivism in L1 writing emphasized students' critical thinking in the writing process by challenging those power structures that had an influence on their lives. In contrast, social constructivism in L2 writing was more pragmatic in that it steered students toward meeting the immediate needs, such as understanding task assignments and structuring appropriate essays, involved in completing their academic writing tasks (Costino

\& Hyon, 2011). Such a significant understanding of the pragmatics of English L2 writing is achieved easily through a social constructivist lens.

Social constructivism and its emphasis on students' sociocultural positions was a decidedly Western approach and therefore first applied to ESL research, rather than EFL. Santos (1992) pointed out that the EFL distinction is an important one because the frame of 
reference in early studies (see e.g. Bizzell, 1978; 1982) focused on American society in the ESL context. However, English L2 critical pedagogy faces different challenges in non-English speaking countries where classroom ideologies may stand in contrast to American ones. Ramanathan and Atkinson (1999) suggested that the application of a social constructivist approach to English L2 writing research was part of the movement of critiques of the notion of written voice. This example further supports the argument that social constructivism is indeed an appropriate lens through which to view EFL writing, as it demands instructors' sociocultural awareness of the student writers' positions in their approaches to writing.

To return to the L2 context, in a special issue of the Journal of Second Language Writing that focused on voice of the L2 writer, Atkinson (2001) expanded on his own L2 writing research and reflected on those of others in the same issue (Matsuda, 2001; Prior, 2001; Ivanič \& Camps, 2001; and Hirvela \& Belcher 2001). Atkinson asserts that voice construction is complex for any writer. He notes that social constructivism provided "modern versions" of the voice concept in these more sophisticated perspectives of voice that were not used to "refurbish" the individualist voice that had been the focus of L2 writing research in the 1990s. Rather, they served as valuable departure points from expressivist process-oriented composition studies. By the early 2000s, L2 writing research paid more attention to social constructivist process-oriented notions in composition, such as Vygotsky's concept of scaffolding (see Vygotsky, 1978).

The Vygotsky-inspired social constructivist focus on L2 writing came in the social interaction of guided development in the form of scaffolding, as described by Donato (1994) focusing on speaking skills, and expanded by Hyland (2003) focusing on L2 writing skills. Scaffolding 
maintains a social constructivist approach that through interaction with a more experienced or knowledgeable other person, learners can participate in the development of their own skills to reach higher competency (Donato, 1994). Hyland (2003) explains in teaching composition, scaffolding comes in the form of heavily assisted instruction in the early stages, with extensive modeling of the writing process. The heavy support in the early stages is then relaxed in order to encourage student writers to actively participate through negotiation of the writing process through peer and tutor feedback, making them more independent, more critical, autonomous writers, eventually able to construct pieces on their own.

With the constructivist focus on the social context and larger community of learners, there has been a major shift away from individually-based L2 writing instruction to instruction that sees knowledge-building as a co-constructed process (Flowerdew \& Miller, 2008). The greatest contribution of social constructivism to education may be the sociocultural theoretical shift in emphasis from knowledge as a product, to knowing as a process, or, knowledge transforming over knowledge telling (see Bereiter \& Scardamalia, 1987). The current social constructivism approaches in L2 writing research range in their specific areas of focus, with most publications discussing epistemological issues related to social constructivism in educational fields including mathematics, science, and social studies, and very few reporting results of studies utilizing social constructivism as a theoretical framework in L2 writing.

Such cultural practices in academic discourse strongly indicate that, as long as there is an interest in EFL writing education in knowledge transforming over knowledge telling, social 
constructivism can provide EFL researchers, instructors, and students alike with much needed perspective.

The elements of cultural practices: Social constructivism as an efficient model for analyzing student writing

This section refers to four recent studies showing a range of applications of social constructivism, including scaffolding (Cotterall \& Cohen, 2003), collaborative writing (Storch, 2005), identity construction (Abasi, Akbari \& Graves, 2006), and intercultural learning experiences (Hung \& Hyun, 2010) in order to argue for the efficacy of social constructivism as a model for analyzing student writing. I first outline the constructs as perspectives of social constructivism from each study before providing an example of the application of social constructivist theory to my suggested text analysis focus areas. This is followed by a final statement of justification for using social constructivism in the approach.

It is significant that Cotterall and Cohen (2003), through a social constructivist perspective, were able to reveal that students who practiced scaffolding took ownership of their writing and established an appropriate rhetorical context, because as mentioned earlier, this is not a universally accepted idea in cross-cultural or EFL writing contexts. The constructs of writer ownership and establishing rhetorical context by EFL writers are both drawn on in the development of my proposed theoretical framework. Taking ownership is a key practice in exercising critical thinking as it results only through the process of writing on a topic in which the writer has a deep level of familiarity. Casanave (2002) explains that "owning research experiences and telling a good story from them" is a writing game strategy that writers can employ when they present themselves in their texts through a high level of 
familiarity with the subject matter. To further support this, in a study at a Japanese university, Stapleton (2001) established that the ability for Japanese EFL students to engage critical thinking in their writing may be hindered or misunderstood by Western assessors due a lack of the students' familiarity with assigned writing topics.

Storch's (2005) study showed that social constructivist theory is crucial to gaining a better understanding of the collaborative stages of the writing process. This article draws on the construct of co-construction of knowledge through working closely with peers and tutors. Abasi, et al. (2006) showed that social constructivism is integral in examining students' awareness of identity construction in their own writing. Accordingly, exploring the critical thinking processes involved in students' awareness of their own writer identity (i.e. understanding their own way(s) of arguing, and self or selves used in their writing) is a central consideration in my theoretical framework. Finally, Hung and Hyun (2010) particularly emphasized the importance of conducting research based in social constructivist theory, and even recommend that further research pursuing issues in this area focus on students' writing.

Social constructivism best serves as the basis for revealing EFL writers' critical argument and writer identity. This is because the focus of the theoretical framework is on the function of the normative concept of learning EFL writing, and the learner's attempt to work out a solution to a practical problem, specifically, developing a critical, cross-cultural self. Social constructivism is therefore a valuable source of theoretical knowledge in this context, because it emphasizes how meanings and understandings grow out of a learner's social interactions. 
From a constructivist perspective, learning does not happen in isolation. It is in the interaction between texts and other people that learning (i.e. knowledge) comes to exist. These interactions of sharing ideas are what establish a learning community where students come to understand the basis for their social and cultural identities. This is crucial to the fundamental understanding of constructivist theory, that the inter-subjective sharing of ideas shapes people's behavior by constituting their interests and identity as members of and participants in an established community.

EFL students-in varying degrees, depending on the instructor-are introduced to challenges to their social and cultural identity in their studies about and in English. University EFL students at the same time take on the challenges of the academic setting in which the contact with the other culture takes place. By combining the intercultural challenges with the academic challenges, the learner then constructs an identity that can be described as cross-cultural, and is then in a better position to make cross-cultural arguments.

The construction of cultural and academic writer identities occurs in social interaction in the cultural and academic communities. Gomez-Estern, et al. (2010, p.232), state:

[I]dentity is generated in social interaction, mediated by cultural instruments, and contextually situated. That is, individuals need to define themselves because they are immersed in social settings in which there is another (individual, social group, or culture). Cultural identity arises from the relationships that individuals maintain with cultural groups, with which they struggle and cooperate (Woodward, 1997).

Should cultural identity be attributed to the individual or the group? Some scholars assert that identity is found in a group, so individuals construct their cultural identity within that group, known as a "collective identity" (Gomez-Estern, et al., 2010, p.233). This idea is significant for my proposed theoretical framework as EFL students may be required, or feel 
culturally obligated to develop their arguments in accordance with their peers-other EFL students who are collectively developing an understanding of the culture of academic writing - through the guidance of their instructor.

\section{How sociocultural conventions shape EFL student writers' critical thinking processes}

The sociocultural conventions of academic writing (i.e. citing evidence, hedging and boosting claims, interpreting the literature to back one's own claims, and addressing counter claims) shape critical thinking processes by requiring writers to integrate identity construction with critical argument, which has been challenged as problematic for students from cultures of collectivist and hierarchical traditions such as Japan's that inherently discourage students from developing a distinct identity or voice in their writing (Atkinson, 1997).

It is important in reference to the argument about Japanese students' critical thinking to provide a working definition of critical thinking. I refer to Ennis's (1998) definition from his article 'Is Critical Thinking Culturally Biased?' in which he explains, "critical thinking is thinking that is reasonable and reflective, and is focused on what to believe or do" (p.16). He goes on to explain that critical thinking is not limited to individuals, and suggests that as long as "group thinking" exists, it can be done critically. With this understanding, the goal of critical thinking, either individual or collective, then is to make reasonable decisions by seeking reasons and alternatives. This understanding also allows a focus on the sociocultural conventions of academic writing in which EFL writers engage in a communicative act and in doing so, establish a sociocultural identity.

The sociocultural identity that I am focusing on is not objectivist or isolated, but instead involves working with the mediation tools used by a collective community in a constructivist 
way-to construct an identity in a social setting. Within the specific focus on the development of academic literacy in the form of writing in a foreign language, it is understood that the use of the sociocultural mediation tools by individuals within that setting influences their language choices (Wertsch, 1998). In the design of the proposed theoretical framework, writing in EFL is a mediation tool developed in an individual's cultural-historical psychology, which is used to construct one's identity. This is because writing (as a mediation tool) is oriented internally and externally at the same time (Bakhtin, 1986; Vygotsky, 1978).

For EFL writers, with the development of a cultural identity comes the development of an academic writer identity. An academic writer identity is made present in the writing in the form of various 'selves' including autobiographical, authorial and/or discoursal (Clark \& Ivanič, 1997). These selves are utilized according to the writer, the task, and sociocultural or socio-political aspect (Ivanič, 1998). The autobiographical self makes use of personal experience as evidence. The authorial self makes demands on the reader by asserting either personal or substantiated claims; through the practice of defending an authorial position, critical thinking processes are employed in the construction of a writer identity that conforms to the value system of the academic discourse community. The discoursal self takes an objective approach, with no personal language, and attributing others in support of claims. These different selves are manifested in the writer's attempts to persuade the reader through different forms of argumentation, which takes place in the final step of establishing a writer identity (see Figure 1). 
In academic writing, representing ideational and interpersonal meanings is manifested in the use of a self or selves, particularly the authorial self. In EFL writing, this has certain implications in that the cultural identity of writers could potentially interfere with the goals of their academic identity. A student writing in EFL may have to make a conscious switch from a cultural identity that expects writing to be inductive to an academic identity that expects writing to display critical thinking through being deductive (Noor, 2001). The meanings in the writing are expected to be equally acceptable for writing teachers as those of a native writer of English, therefore EFL writers attempt approaches to writing that are more typical of native English writers. However, the suggestion that EFL student writers are unable to make this switch is problematic. In a case where these writers were required to make the switch, they were reportedly successful. In Stapleton's (2001) study, he took writing samples (of responses to provocative essays he wrote) from 45 undergraduate students in courses with the title "English Writing" in order to propose a model of assessment for critical thinking. In this study Stapleton concluded that, "participants demonstrated a fundamental understanding that all opinions require support" (p.526) and wrote with "individualized voices, which are closely related to critical thinking ability" (p. 534). Furthermore, students who lack background knowledge about or some level of familiarity with their assigned topic are less likely to demonstrate the ability to think critically due to "a lack of shared assumptions between the non-Asian researchers and their Japanese students" (Stapleton, 2001, p.530). 
Critical thinking research: The phenomenon of exercising critical thinking in presenting an argument in EFL writing

There are several components that influence the development of critical argument for EFL student writers who make attempts at persuading readers in the writing process. They experiment with ideas presented in EFL and culture, and work through different forms of argumentation. The various forms of argumentation (e.g. borrowing or building one from the reading, or basing it on one's own schemata then locating claim support) are usually introduced by L2 writing teachers to provide students with a set of approaches that they can use to persuade their readers (by interacting with appropriate supporting evidence from their established position). Student writers may experiment with the language by trying out various stylistic techniques (e.g. displaying a discoursal self in the form of a social or political commentator in an attempt to establish ethos, displaying an authorial self by referring to well-established concepts in utilizing logos, or displaying an autobiographical self in the form of personal anecdotes that may instigate pathos) in an attempt to make use of the most persuasive identity, or self (Clark \& Ivanič, 1997).

Regarding the various forms of argumentation, student writers will usually take one of two approaches when presenting an argument. Both approaches have implications for writer identity and critical thinking. One approach involves the student writer "borrowing" the argument from relevant sources. The writer then uses the borrowed argument as the thesis. This way of forming an argument is rather common for EFL writers in their attempt to make their writing appear "native" (Stapleton, 2002). When using this approach, EFL student writers mimic features of both language and perspective from their sources (McKinley, 
2013). This practice can lead to a loss of the writer's voice, and possibly an inability to display critical thinking skills. In contrast, the other approach to arguing is when writers essentially defend a position on a topic that has been developed themselves based on their own schemata. This approach is a social-cultural practice, the enactment of which, emphasized by academics including Kubota (1999) and Stapleton (2002), involves critical thinking processes. The approach requires student writers to establish their own argument in the thesis that is not necessarily based on ideas from outside sources (Stapleton, 2001). Critical reasoning is required in this approach to develop the argument.

The focus on critical thinking in student writers' development of critical argument is crucial to my theoretical framework. However, there has been well-documented deliberation on the value or damage of focusing on critical thinking in developing critical argument in writing classrooms (Benesch, 1991; Phelan, 2001). Atkinson (1997) points out that although there is some confusion among educators about how critical thinking is supposed to function in academic writing, it is nevertheless vital to success in higher education. Davies (2003, pp.12) states:

[S]kills in critical reasoning are as important for educational success as is mastering linguistic genres associated with particular fields of study and vice-versa-both skills are equally necessary for good academic performance: "Poor English and poor argument or analysis [are] inextricably linked" (Felix \& Lawson, 1994, p. 67).

Davies (2003) continues, "For students, especially students from non-English speaking backgrounds (NESB) the 'specter' of critical thinking, not writing, is usually their single greatest fear" (p.2). The implications of this for the framework are significant in that if the specter of critical thinking is indeed non-English speaking students' single greatest fear, then 
the development of critical thinking is the ideal focus in an analysis of students learning to write in English.

As described earlier, the development of social constructivist theory in EFL writing research led to a focus on student writers' shifts from internalizing to externalizing. Having completed the process of establishing and confirming cultural and academic writer identities, an individual is then able to use that knowledge/awareness of the identities in relation to the academic community. Within the academic community the EFL student writer negotiates mediated action-often in the form of working with peer and teacher feedback as well as teacher instruction-accomplishing the social action of interacting with tutors and examiners for assessment. This kind of social interaction requires EFL students to think critically in their adaptation to the academic community within which their writing occurs; it is also necessary to make this critical thinking and writer identity evident in their written texts in order for them to be successful in their assessment. Along with mediated action, EFL student writers also negotiate intercultural challenges in order to attempt to argue a point. Through additional feedback, the EFL student writer then has the ability to argue critically and persuade readers and display an appropriate writer identity within the academic community.

To explore EFL students' development of critical thinking in learning academic English writing, it is appropriate to focus on it as a form of semiotic mediation with consideration given to the "social, cultural, and historical situatedness of mediated action" (Wertsch, 1993, p.8). Wertsch (1993) explains that the notion of mediated action sees human action as inherently affected by social, cultural and historical aspects, and suggests using it as a "unit 
of analysis" (p.119) in social constructivist research. The understanding of human action as a unit of analysis allows me to conceptualize the identities of the student participants as active members of a social, academic community. It also allows a focus on action mediated by tools (i.e. EFL writing) in order to analyze both the writer and the cultural instruments used in the writing as co-existing. Those tools shape the writer's act of identification. The focus on action is essential as it avoids the idea of identity formation represented by discourse, but rather looks at the social construction of that discourse. It is a particularly useful paradigm to see identity as a communicative action, as it allows for the understanding that identities can change depending on the activity (Ivanič, 1998).

The relationship of this concept of identity to critical argument is one of due process. In a situation where a learner is presented with reading and writing skills-in my theoretical framework, in EFL-it is understood that this is only the beginning, and the end point is the mastering of the particular discursive instruments of "ways of arguing" (see "attempts to persuade" in Figure 1), which allow the learner to appropriate the cultural resources of the target language (Gomez-Estern, et al., 2010, p.238). This process involves two steps: the first is the acquiring of new mediation tools in the target language to organize social interactions, which then leads to the second step of regulating ways of thinking in the target language. It is inevitable that when learners take on these new tools in another language, this will change their schemata and understanding of themselves and their own sociocultural identities.

\section{The proposed theoretical framework}

Based on issues outlined in this paper, surrounding the three elements of sociocultural theory, writer identity, and critical thinking, the following theoretical framework is a way to 
unite these theories into a visual representation of the construction of critical thinking and argumentation in L2 writing.

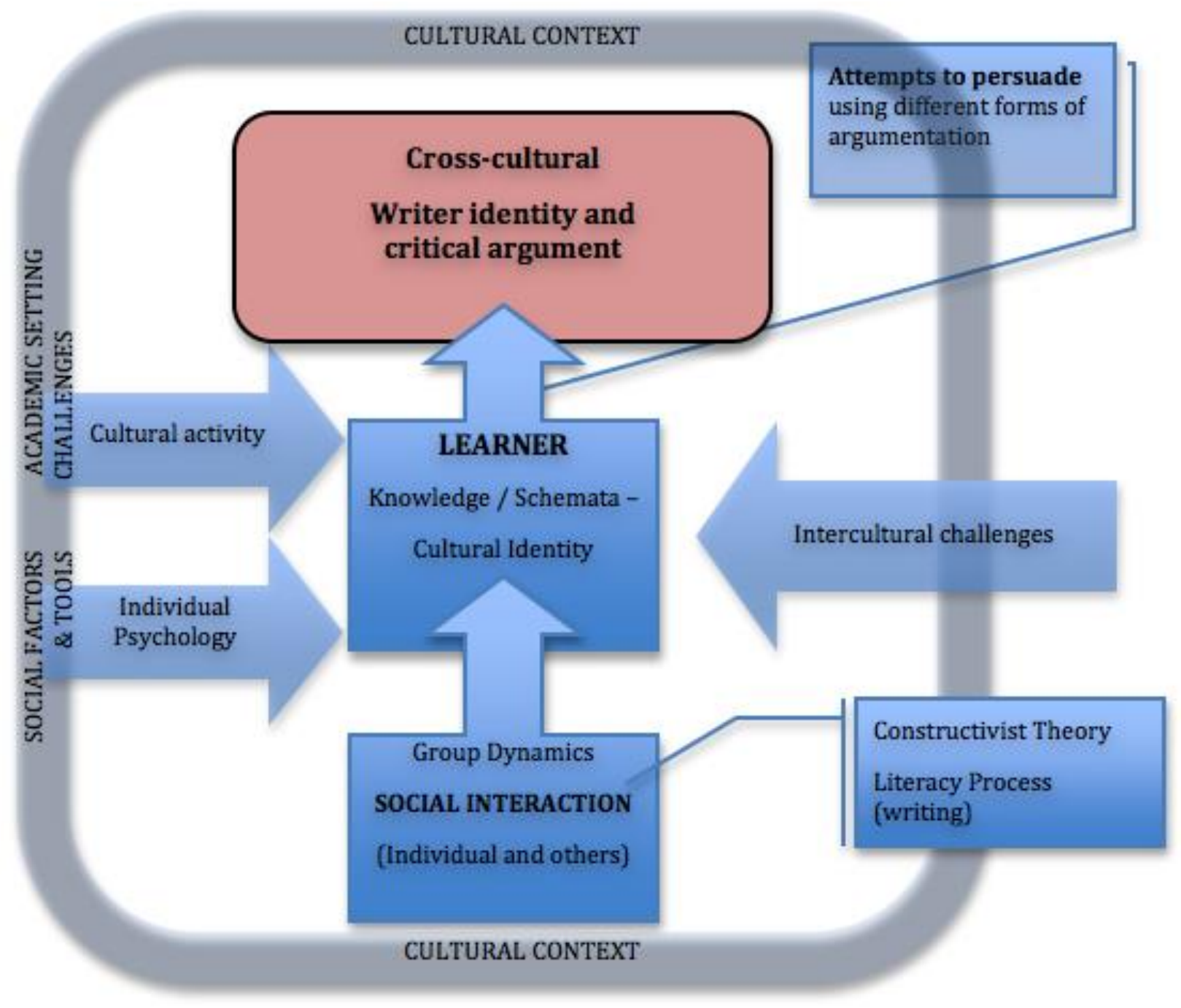

Figure 1: Theoretical framework of general concepts

The diagram's focus is on the learner, specifically, the learner's knowledge, schemata, and cultural identity. Below that central shape in the diagram is social interaction between the individual and others (in pair and group work), which is the basis for what creates the learner's awareness of all of these aspects. The movement from social interaction to the learner is labeled "group dynamics". This is different from the "individual psychology" 
feeding in to the learner through social factors and tools prescribed by the learner's cultural context. The box to the right identifies the theory, linguistic focus, and process underlying the group dynamics, namely constructivist theory and the literary process. Also, feeding in from the cultural context is cultural activity manifested in academic setting challenges (what could be labeled "classroom dynamics"). The final influence feeding in to the learner is the intercultural challenge from outside the cultural context. In EFL studies, this is the introduction of English as a foreign language/culture. All of this then gets developed as the learner makes attempts at persuasion through experimentation with the new language/culture in different forms of argumentation (usually through teacher-guided tasks in a classroom or for an assignment). It is this attempt (labeled "attempts to persuade" in the box to the right) that, if understood by the learner to be an exercise in critical thinking, then leads the learner to a better position from which to establish a cross-cultural identity and to develop a cross-cultural critical argument.

\section{The implications of the framework}

To offer a culminating argument as to how the interrelations between the three main components make the proposed theoretical framework a robust model that accounts for the challenges and achievements of student writers, I refer to the applicability of the framework in a large, recent study.

This framework was used as the base theory for a large study that took place at a university in Japan (McKinley, 2012). In this investigative study, two students, given the pseudonyms Satoko and Aya, in the same writing class had two very different experiences with their task of writing an argumentative research paper, one much more successful than the other. 
Satoko's topic explored universal health care in the US, and Aya's topic was on the right to wear religious clothing in schools. These students discovered their ability to establish a strong argument was contingent on their academic community. Their teacher divided the class into three groups according to the students' topics, generating smaller, more intense academic communities in which the students needed to construct their cultural and academic identities. Satoko was in a group on American studies, which was beneficial seeing as her position was based on her own schemata-she had lived in the US, and had firsthand experience with the healthcare system. Aya was put in a group of students with mixed topics, which caused a great deal of strain as she struggled to find ways to negotiate with her group and argue critically about her topic, having no background experience with the subject matter, but building it based on her analysis of sensationalized media articles.

In interviews with Satoko's and Aya's teacher, a discussion of writer identity was raised in relation to classroom observation data. The teacher explained that in working with the sociocultural conventions of academic discourse, he emphasized the importance for the students to use a discoursal self (although not using this term), in order to get students to focus on identifying, interacting with, and using appropriate sources for support rather than their own ideas. For Satoko, whose writing context was very much represented by the proposed theoretical framework, and who found and successfully used reliable sources on her topic and a supportive research group, this worked well. Aya's experience, however, did not fit the flow of the framework-her sources were weak, and she was not able to use them effectively. She ultimately relied almost entirely on a kind of muddled discoursal-authorial self to make her argument. It was no surprise for the students when Satoko received an A grade for the course while Aya received a C. Their teacher expressed frustration, wishing to 
help Aya to experience the course the way Satoko did-something perhaps more achievable if the teacher had had an understanding of the proposed theoretical framework and could have better guided Aya.

\section{Conclusion}

This article has shown how critical thinking processes are shaped by awareness of the sociocultural conventions of academic discourse, and how critical thinking arises from a writer identity aligned with the culture of English academic writing.

The fundamental link between the theories/components mentioned in this article is the social constructivist understanding of an interpersonal collaborative construction of knowledge. Sociocultural theory, identity construction theory and critical argument theory are all crucial to gaining an understanding of the process of students learning academic EFL writing. This is because it is helpful for EFL writing teachers and researchers to examine the development of these students' ideas about critical thinking and how it is applied in the writing classroom. Teachers and researchers can also examine how students' critical thinking is applied to their writing, with careful consideration of the students' sociocultural contexts. Understanding EFL students' written texts using the theoretical framework proposed in this article makes this kind of examination achievable for teachers, researchers, and students alike.

To conclude, the implications of the theoretical framework discussed in this article are substantial. The framework allows for a focused analysis on EFL writers' critical argument and writer identity, revealing important considerations both theoretically and pedagogically. In terms of theory, these two focus points are inseparable. While issues 
related to EFL student writers' voice may be debated, suggesting that identity can be ignored in analysis of such students' critical argument would be detrimental to future studies. Pedagogically, while it is not my intention to suggest EFL writing teachers should teach writer identity in their classes, students can benefit if teachers understand how to locate their students' writer identities in order to address their writing needs and to successfully relay the expectations of writing tasks. Students would more easily meet task expectations if they know to write arguments using an autobiographical self, authorial, and/or discoursal self.

This analysis of relevant literature and development of a potentially valuable theoretical framework in utilizing social constructivism forms a base theory focused on critical argument and writer identity. I recommend that future research in EFL writing make use of this framework as it effectively reveals a depth of understanding about EFL student writers' attempts to establish appropriate selves as required by their learning contexts.

\section{References}

Abasi, A.R., Akbari, N., Graves, B. (2006). Discourse appropriation, construction of identities, and the complex issue of plagiarism: ESL students writing in graduate school. Journal of Second Language Writing 15(2), 102-117.

Atkinson, D. (1997). A critical approach to critical thinking in TESOL. TESOL Quarterly, 31(1), 71-94.

Atkinson, D. (2003). Writing and culture in the post-process era. Journal of Second Language Writing, 12(1), 49-63. 
Bakhtin, M.M. (1986). Speech genres and other late essays. Edited by M. Holquist, translated by V.W. McGee. Austin: University of Texas Press.

Barton, E.L. (1995). Contrastive and non-contrastive connectives. Written Communication, 12(2), 219-239.

Benesch, S. (2001). Critical English for Academic Purposes: Theory, Politics and Practice. Mahwah, NJ: Lawrence Erlbaum.

Bereiter, C. \& Scardamalia, M. (1987). The psychology of written composition. Hillsdale, NJ: Erlbaum.

Bizzell, P.L. (1978). The Ethos of Academic Discourse. College Composition and Communication, 29(4), 351-355.

Bizzell, P.L. (1982). Cognition, convention, certainty: Knowledge about writing, Pre/Text, 3, 213-243.

Clark, R., \& Ivanič, R. (1997). The Politics of Writing. New York: Routledge.

Costino, K.A. \& Hyon, S. (2011). Sidestepping our "scare words": Genre as a possible bridge between L1 and L2 compositionists. Journal of Second Language Writing 20, 24-44.

Cotterall, S. \& Cohen, R. (2003). Scaffolding for second language writers: producing an academic essay. ELT Journal 57(2), 158-166.

Creswell, J.W. (2009). Research Design: Qualitative, Quantitative, and Mixed Methods Approaches. Thousand Oaks, CA: Sage.

Davies, W. (2003). A cautionary note about the teaching of critical reasoning. In Learning for an Unknown Future, Proceedings of the 26th HERDSA Annual Conference, Christchurch, New Zealand, 134 pages, Retrieved from http://www.herdsa.org.au/wpcontent/uploads/ conference/2003/papers/HERDSA70.pdf 
Donato, R. (1994). Collective scaffolding in second language learning. In J.P. Lantolf and G. Appel (Eds.), Vygotskian Approaches to Second Language Research (pp.33-56). Westport, CT: Ablex Publishing.

Eemeren, F.H. van, \& Grootendorst, R. (1984). Speech acts in argumentative discussions: A theoretical model for the analysis of discussions directed towards solving conflicts of opinion, Dordrecht, The Netherlands: Floris Publications.

Eemeren, F.H. van, \& Grootendorst, R. (1992). Argumentation, communication, and fallacies: A pragma-dialectical perspective. Hillsdale, NJ: Lawrence Erlbaum.

Elbow, P. (1973). Writing Without Teacher. New York: Oxford University Press.

Flowerdew, J. \& Miller, L. (2008). Social Structure and Individual Agency in Second Language Learning: Evidence from Three Life Histories. Critical Inquiry in Language Studies, 5(4), 201-224.

Giroux, H.A. (1994). Toward a pedagogy of critical thinking. In K.S. Walters (Ed.), ReThinking Reason: New Perspectives in Critical Thinking (pp.200-201). Albany, NY: SUNY Press.

Gómez-Estern, B.M., Amián, J.G., Sánchez Medina, J.A., \& Marco Macarro, M.J. (2010). Literacy and the Formation of Cultural Identity. Theory Psychology 20(2), 231-250. Greene, S. \& J. M. Ackerman. (1995). Expanding the constructivist metaphor: A rhetorical perspective on literary practice. Review of Educational Research 65(4), 383-420. Halliday, M.A.K. (1978). Meaning and the construction of reality in early childhood. In H.L. Pick \& E. Salzman (Eds.), Modes of perceiving and processing of information (pp. 67-96). Hillsdale, NJ: Erlbaum. 
Halliday, M.A.K. (1994). Language as Social Semiotic. In J. Maybin (Ed.) Language and literacy in social practice: a reader (pp.23-43). Clevedon, UK: Multilingual Matters.

Hirvela, A. \& Belcher, D. (2001). Coming back to voice: The multiple voices and identities of mature multilingual writers. Journal of Second Language Writing, 10 (1-2), 83-106.

Hung, H.L. \& Hyun, E. (2010). East Asian international graduate students' epistemological experiences in an American University. International Journal of Intercultural Relations $34,340-353$.

Hyland, K. (2003). Second Language Writing. Cambridge, UK: Cambridge University Press. Hyland, K. (2004). Disciplinary Discourses: Social Interactions in Academic Writing. Ann Arbor, MI: University of Michigan Press/ELT.

Hyland, K. (2008). Writing Theories and Writing Pedagogies. Indonesian Journal of English Language Teaching 4(2), 91-110.

Ivanič, R. (2004). Discourses of writing and learning to write. Language and Education, 18(3), 220-245.

Ivanič, R. \& Camps, D. (2001). I am how I sound: Voice as self-representation in L2 writing. Journal of Second Language Writing, 10(1-2), 3-33.

Kubota, R. (1999). Japanese culture constructed by discourses: Implications for applied linguistics research and ELT. TESOL Quarterly, 33(1), 9-35.

Lantolf, J.P. \& Thorne, S.L. (2006). Sociocultural Theory and the Genesis of Second Language Development. Oxford, UK: Oxford University Press.

Matsuda, P.K. (2001). Voice in Japanese written discourse Implications for second language writing. Journal of Second Language Writing, 10, 35-53.

McKinley, J.G. (2012). A study of university students in Japan: Learning and application of 
academic English writing. Victoria University of Wellington. Retrieved from http://researcharchive.vuw.ac.nz/xmlui/bitstream/handle/10063/2053/thesis.pdf?se quence $=1$

McKinley, J. (2013). Displaying Critical Thinking in EFL Academic Writing: A Discussion of Japanese to English Contrastive Rhetoric. RELC Journal, 44(2), 195-208.

McKinley, J. (2014). The impact of Western criticisms of Japanese rhetorical approaches on learners of Japanese. Language Learning in Higher Education, 4(2), 303-319.

Noor, R. (2001). Contrastive rhetoric in expository prose: Approaches and achievements. Journal of Pragmatics, 33(2), 255-269.

Phelan, J. (2001). On Teaching Critical Arguments: A Matrix of Understanding. Pedagogy 1(3), 527-538.

Prior, P. (2001). Voices in text, mind, and society: Sociohistoric accounts of discourse acquisition and use. Journal of Second Language Writing, 10(1-2), 55-81.

Ramanathan, V. \& Atkinson, D. (1999). Individualism, Academic Writing, and ESL Writers. Journal of Second Language Writing, 8(1), 45-75.

Santos, T. (1992). Ideology in Composition: L1 and ESL. Journal of Second Language Writing, 1(1), 1-15.

Scollon, R. (1994). As a matter of fact: The changing ideology of authorship and responsibility in discourse. World Englishes, 13, 34-46.

Simon, S.D. (2010). The Principles of Constructivism, 9 pars., Retrieved from www.des.emory.edu/mfp/502/502cons.PDF

Sokol, M. (2005). Academic Identity Construction in E-discussion Lists: A Case Study. In G. Cortese \& A. Duszak (Eds.), Identity, Community, Discourse: English in Intercultural 
Settings (pp.321-344). Bern, Switzerland: Peter Lang.

Stapleton, P. (2001). Assessing Critical Thinking in the Writing of Japanese University Students: Insights About Assumptions and Content Familiarity. Written Communication, 18(4), 506-548.

Stapleton, P. (2002). Critiquing voice as a viable pedagogical tool in L2 writing: Returning the spotlight to ideas. Journal of Second Language Writing, 11, 177-190.

Stetsenko, A. \& Arievitch, I. (1997). Constructing and deconstructing the self: Comparing post-Vygotskian and discourse-based versions of social constructivism. Mind, Culture, and Activity, 4, 160-173.

Storch, N. (2005). Collaborative writing: Product, process, and students' reflections. Journal of Second Language Writing, 14, 153-173.

Vianna, E. \& Stetsenko, A. (2006). Embracing History through Transforming It: Contrasting Piagetian versus Vygotskian (Activity) Theories of Learning and Development to Expand Constructivism within a Dialectical View of History. Theory \& Psychology, 16(1), 81-108.

Vygotsky, L.S. (1978). Mind in society. The development of higher psychological functions, M. Cole, V. John-Steiner, S. Scribner, \& E. Souberman (Eds.); M. Cole\& M. Lopez-Morillas (Trans.). Cambridge, MA: Harvard University Press.

Wertsch, J.V. (1993). Voices of the Mind: Sociocultural Approach to Mediated Action. Cambridge, MA: Harvard University Press. 